\title{
HUBUNGAN JENIS PERSALINAN DENGAN KEJADIANASFIKSIA NEONATORUM DI RSUP PROF. DR. R.D. KANDOU MANADO
}

\author{
${ }^{1}$ Zulkarnain Zainuddin \\ ${ }^{2}$ Rocky Wilar \\ ${ }^{3}$ Max F.J. Mantik
}

\author{
Bagian Ilmu Kesehatan Anak Universitas Sam Ratulangi Manado \\ Email: zulensv3@gmail.com
}

\begin{abstract}
Neonatal Asphyxia is a condition of newborns who fail to breathe spontaneously and regularly soon after birth.Asphyxiais one ofthe causes ofmortalityandmorbidityof newborns. In Prof Dr. Dr. R. D Kandou Manado neonatal asphyxia was ranked 7 out of 10 perinatology disease by 2011 as many as 50 cases. There are several factors that trigger the occurrence of asphyxia eclampsia, fetal distress, abruptio placenta, placenta previa, and the state of maternal and others fetal distress. This study is a retrospective analytical taken in the form of medical records of the period July 2010 - July 2012. The total sampel of 100 samples were divided into 50 infants asphyxia and 50 infants of non asphyxia. The data were processed using SPSS version 16. Statistical tests were conducted to prove the hypothesis with chi square test. The results showed a significant relationship between type of delivery and neonatal asphyxia ( $\mathrm{P}=$ 000 ), where the Caesarean section delivery with the largest percentage of asphyxia in infants that is 31 infants (62\%). Highly significant correlation between the type of childbirth with the incidence of asphyxia. Caesarean section with the largest percentage due mostly done when the mother and fetus during an emergency such as fetal distress, eclampsia, preeclampsia, fetal abnormalities layout, narrow pelvis, oligohydramnios, premature rupture of membranes, and prolonged labor.
\end{abstract}

Keywords: Asphyxia neonatorum, type of childbirth

\begin{abstract}
Abstrak:Asfiksia neonatorum adalah suatu keadaan bayi baru lahir yang gagal bernafas secara spontan dan teratur segera setelah lahir. Asfiksia merupakan salah satu penyebab mortalitas dan morbiditas bayi baru lahir. Di RSUP Prof. Dr. R.D Kandou Manado asfiksia neonatorum menduduki peringkat 7 dari 10 penyakit perinatologi pada tahun 2011 sebanyak 50 kasus. Ada beberapa faktor pencetus terjadinya asfiksia yaitu eklampsia, gawat janin, solusio plasenta, plasenta previa, dan keadaan gawat ibu dan janin lainnya. Penelitian ini bersifat analitik retrospektif yang diambil dalam bentuk rekam medis periode juli 2010 - juli 2012. Besar sampel sebanyak 100 sampel yang terbagi atas 50 bayi asfiksia dan 50 bayi non asfiksia.Data diolah menggunakan SPSS versi 16.Uji statistik dilakukan untuk membuktikan hipotesis dengan uji chi square. Hasil penelitian menunjukkan adanya hubungan yang bermakna antara jenis persalinan dan asfiksia neonatorum $(\mathrm{P}=000)$, dimana persalinan seksio sesarea dengan presentase terbesar pada bayi asfiksia yakni 31 bayi (62\%). Adanya hubungan yang sangat bermakna antara jenis persalinan dengan kejadian asfiksia.Seksio sesarea dengan presentase terbesar dikarenakan kebanyakan dilakukan apabila ibu maupun janin dalam keadaan darurat misalnya gawat janin, eklamsia, preeklamsia, kelainan letak janin, panggul sempit, oligohidramnion, ketuban pecah dini, dan partus lama.
\end{abstract}

Kata Kunci: Asfiksia neonatorum, jenis persalinan. 


\section{Latar Belakang}

Asfiksia Neonatorum adalah suatu keadaan bayi baru lahir yang gagal bernafas secara spontan dan teratur segera setelah lahir. Asfiksia neonatorum dapat menyebabkan hipoksemia, hiperkapnia, dan asidosis. ${ }^{1}$

Ada beberapa faktor pencetus terjadinya asfiksia neonatorum yaitu faktor ibu (hipoksia, eklampsi, toksemia, hipotensi karena perdarahan, diabetes melitus, kelainan jantung, atau penyakit ginjal), faktor plasenta (gangguan pertukaran gas antara ibu dan janin dipengaruhi oleh luas dan kondisi plasenta, misalnya solusio plasenta atau plasenta previa), faktor fetus (janin terlilit tali pusat, tali pusat menumbung, dll), dan faktor persalinan (partus lama, kelahiran sungsang, kembar, seksio sesarea, dan proses persalinan abnormal lainnya). ${ }^{2}$

Asfiksia merupakan salah satu penyebab mortalitas dan morbiditas bayi baru lahir dan akan membawa berbagai dampak pada periode neonatal baik di negara berkembang maupun di negara maju.Di negara maju angka kejadian asfiksia berkisar antara 1-1,5\% dan berhubungan dengan masa gestasi dan berat lahir. Di negara berkembang angka kejadian bayi asfiksia lebih tinggi dibandingkan di negara maju karena pelayanan antenatal yang masih kurang memadai. Sebagian besar bayi asfiksia tersebut tidak memperoleh penanganan yang adekuat sehingga banyak diantaranya meninggal. ${ }^{3}$

Menurut WHO deperkirakan sekitar 900.000 kematian bayi baru lahir setiap tahun diakibatkan oleh asfiksia neonatorum.Laporan dari Organisasi Kesehatan Dunia (WHO) menyebutkan bahwa sejak tahun 2000-2003 asfiksia menempati urutan ke-6, yaitu sebanyak 8\%, sebagai penyebab kematian anak diseluruh dunia setelah pneumonia, malaria, sepsis neonatorum dan kelahiran prematur. ${ }^{4-6}$

Menurut National Center for Health Statistics (NCHS) pada tahun 2002, asfiksia neonatorum mengakibatkan 14 kematian per 100.000 kelahiran hidup di Amerika Serikat. $^{7}$

Di Indonesia mempunyai 200 juta penduduk dengan angka kelahiran 2,5\%/tahun sehingga diperkirakan terdapat 5 juta kelahiran per tahun. Jika angka kejadian asfiksia 3-5\% dari seluruh kelahiran, diperkirakan 250 ribu bayi asfiksia lahir pertahun. Menurut hasil riset kesehatan dasar tahun 2007, tiga penyebab utama kematian perinatal di Indonesia adalah gangguan pernapasan/respiratory disorders $(35,9 \%)$, prematuritas $(32,4 \%)$ dan sepsis neonatorum $(12.0 \%){ }^{8}$

Di Bagian Ilmu Kesehatan Anak FKUI-RSCM pada tahun 2000 didapatkan $6,3 \%$ bayi asfiksia dari seluruh kelahiran, 2,1\% diantaranya lahir dengan asfiksia berat. ${ }^{3}$ Di RS Dr Kariadi Semarang selama tahun 2007, angka kelahiran bayi hidup mencapai 1600 jiwa setahun dengan angka kejadian bayi lahir dengan asfiksia berjumlah 187 kelahiran.

Hasil penelitian sebelumnya di RSUD dr. M. Soewandhie Surabaya periode Januari 2010 Juni 2011 didapatkan sebanyak 73,0 \% dari jenis persalinan tindakan bayi mengalami asfiksia neonatorum, sedangkan $66,9 \%$ dari jenis persalinan normal bayi tidak mengalami asfiksia neonatorum. Artinya jenis persalinan tindakan mempunyai resiko 5,471 kali lebih 
besar terhadap kejadian asfiksia neonatorum dibandingkan dengan persalinan normal.. ${ }^{9}$

\section{Metode Penelitian}

Penelitian ini merupakan penelitian Penelitian ini merupakan penelitian Analitik Retrospektif. Tempat penelitian dilaksanakan di instalasi rekam medik BLU di RSUP Prof. Dr. R.D. Kandou Manado. Waktu pelaksanaan pada bulan November - Desember 2012. Populasi bayi yang menderita asfiksia neonatorum yang dirawat di Sub.Bagian Neonatal RSUP Prof. Dr. R.D Kandou Manado periode Juli 2010 - Juli 2012. Sampel yang diteliti adalah data rekam medis bayi yang menderita asfiksia neonatorum yang dirawat di Sub.Bagian Neonatal RSUP Prof. Dr. R.D Kandou Manado periode Juli 2010 - Juli 2012. Besar sampel dihitung dengan menggunakan rumus menentukan besar sampel :

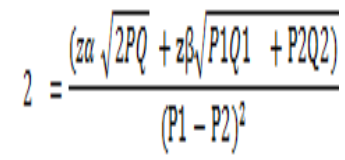

Sehingga didapatkan jumlah sampel yang diperlukan dalam penelitian adalah 105.

Kriteria inklusi ialah bayi baru lahir yang menderita asfiksia neonatorum.Kriteria ekslusi bayi dengan kelainan bawaan. Variabel bebas yaitu jenis persalinan, Indikasi persalinan. Variabel terikat yaitu asfiksia neonatorum.

Cara kerja yaitu mengumpulkan data-data bayi yang menderita asfiksia beserta jenis persalinan dari rekam medik BLU di RSUP Prof. Dr. R.D. Kandou
Manado periode Juli 2010 - Juli 2012. Mengelola dan menganalisis data kasus berdasarkan variabel penelitian secara manual dan menggunakan SPSS versi 20. Data tersebut di hitung dan disajikan dalam bentuk teks dan tabel, kemudian dianalisa untuk mengetahui frekuensi dari jeni-jenis persalinan yang menyebabkan asfiksia neonatorum.

\section{Hasil Penelitian}

Hasil penelitian didapatkan sampel sebanyak 105 bayi yang menderita asfiksia neonatorum di BLU RSUP.Prof. Dr. R.D. Kandou Manado periode juli 2010 - juli 2012 yang memenuhi kriteria dalam penelitian ini.

Selama melakukan penelitian selama 2 bulan mengenai hubungan jenis persalinan terhadap kejadian asfiksia neonatorum di RSUP Prof. Dr. R.D Kandou Manado periode juli 2010 - juli 2012 didapatkan jumlah bayi yang menderita asfiksia sebanyak 105 yang memenuhi kriteria didapatkan tertinggi 66 bayi laki-laki $(62,9 \%)$ dan terendah 39 perempuan $(37,1 \%)$.

Tabel 1. Distribusi sampel penderita asfiksia neonatorum berdasarkan jenis kelamin

\begin{tabular}{ccc}
\hline $\begin{array}{c}\text { Jenis } \\
\text { Kelamin }\end{array}$ & Jumlah & $\begin{array}{c}\text { Persen } \\
(\boldsymbol{\%})\end{array}$ \\
\hline Laki-laki & 66 & $62,9 \%$ \\
Perempuan & 39 & $37,1 \%$ \\
\hline Jumlah & 105 & $100 \%$ \\
\hline
\end{tabular}

Dari 105 sampel yang menderita asfiksia neonatorum didapatkan jenis persalinan tertinggi seksio sesarea sebanyak 60 bayi $(57,1 \%)$, sebanyak 25 bayi $(23,8 \%)$ dengan spontan letak belakang kepala, 13 bayi $(12,4 \%)$ dengan 
ekstaksi vakum, 5 bayi $(4,8 \%)$ spontan bracht, dan jenis persalinan terendah yaitu ekstraksi forceps hanya 2 bayi $(1,9 \%)$. Tabel 2 menunjukkan bahwa setelah dilakukan uji kemaknaan dengan chisquare maka didapatkan adanya hubungan bermakna antara jenis persalinan dengan asfiksia neonatorum $(\mathrm{P}=0,00)$. Dari jenis persalinan seperti seksio sesarea, ekstraksi vakum, dan ekstraksi forceps di indikasikan karena dimana ibu dan janin dalam keadaan gawat darurat yakni gawat janin, preeklamsia berat, preeklamsia ringan, letak sungsang, letak lintang, eklampsia, ketuban pecah dini, oligohidramnion, makrosomia, dan cephalopelvic disproportion. Sedangkan persalinan spontan belakang kepala dan spontan bracht tidak terdapat indikasi.

Tabel 2. Distribusi sampel penderita asfiksia neonatorum berdasarkan jenis persalinan

\begin{tabular}{cccc}
\hline $\begin{array}{c}\text { Jenis } \\
\text { Persalinan }\end{array}$ & Jumlah & $\begin{array}{c}\text { Persen } \\
(\%)\end{array}$ & P \\
\hline $\begin{array}{c}\text { Seksio } \\
\text { Sesarea }\end{array}$ & 60 & $57,1 \%$ & \\
$\begin{array}{c}\text { Spontan } \\
\text { LBK }\end{array}$ & 25 & $23,8 \%$ & \\
$\begin{array}{c}\text { Ekstraksi } \\
\text { Vakum }\end{array}$ & 13 & $12,4 \%$ & $000 *$ \\
$\begin{array}{c}\text { Spontan } \\
\text { bracht }\end{array}$ & 5 & $4,8 \%$ & \\
$\begin{array}{c}\text { Ekstraksi } \\
\text { Forseps }\end{array}$ & 2 & $2 \%$ & \\
\hline Jumlah & 105 & $100 \%$ & \\
\hline Ket : * chi-square & &
\end{tabular}

Dari besar sampel yang didapat sebesar 105 didapatkan berat badan lahir bayi yang menderita asfiksia neonatorum < $1000 \mathrm{gr}$ sebanyak 7 bayi $(6,67 \%)$, 1000gr 2499 gr sebanyak 14 bayi $(13,33 \%)$,
2500 gr - 3999 gr sebanyak 79 $(75,24 \%)$, dan > 4000 gr hanya didapat 5 bayi $(4,76 \%)$. Dari hasil analisa frekuensi didapatkan berat badan rata-rata 2866,19 gr. Didapatkan berat badan terendah yaitu $650 \mathrm{gr}$, sedangkan berat badan tertinggi yakni 5000 gr. Didapatkan juga 21 bayi dengan berat badan lahir rendah (BBLR) 7 bayi diantaranya prematur. Rincian jumlah dapat dilihat pada tabel 3 .

Tabel 3. Distribusi sampel penderita asfiksia neonatorum berdasarkan berat badan lahir

\begin{tabular}{ccc}
\hline $\begin{array}{c}\text { Berat } \\
\text { Badan } \\
\text { Lahir }\end{array}$ & Jumlah & $\begin{array}{c}\text { Persen } \\
(\%)\end{array}$ \\
\hline$<1000 \mathrm{gr}$ & 7 & $6,67 \%$ \\
$1000 \mathrm{gr}-$ & 14 & $13,33 \%$ \\
$2499 \mathrm{gr}$ & & \\
$2500 \mathrm{gr}-$ & 79 & $75,24 \%$ \\
$3999 \mathrm{gr}$ & & \\
$>4000 \mathrm{gr}$ & 5 & $4,70 \%$ \\
\hline Jumlah & 105 & $100 \%$ \\
\hline
\end{tabular}

Dari 105 sampel bayi asfiksia neonatorum didapatkan $<40 \mathrm{~cm}$ sebanyak 13 bayi $(12,38 \%), 41 \mathrm{~cm}-$ $49 \mathrm{~cm}$ sebanyak 61 bayi $(58,1 \%)$, dan > $50 \mathrm{~cm}$ sebanyak 31 bayi $(29,52 \%)$. Data tersebut dapat dilihat pada tabel 4.

\section{Tabel 4.Distribusisampel penderita} asfiksia neonatorum berdasarkan panjang badan.

\begin{tabular}{ccc}
\hline $\begin{array}{c}\text { Panjang } \\
\text { Badan }\end{array}$ & Jumlah & $\begin{array}{c}\text { Persen } \\
(\boldsymbol{\%})\end{array}$ \\
\hline$<40 \mathrm{~cm}$ & 13 & $12,3 \%$ \\
$41 \mathrm{~cm}-49$ & 61 & $58,1 \%$ \\
$\mathrm{~cm}$ & & \\
$>50 \mathrm{~cm}$ & 31 & $29,52 \%$ \\
\hline Jumlah & 105 & $100 \%$ \\
\hline
\end{tabular}




\section{Pembahasan}

Hasil yang didapatkan dari penelitian di BLU RSUP Prof. Dr. R.D. Kandou Manado periode juli 2012 - juli 2012 didapatkan sampel sebanyak 105 bayi menderita asfiksia neonatorum. Dimana terdapat jumlah bayi laki-laki lebih banyak daripada bayi perempuan yaknididapatkan 66 bayi laki-laki (62,9\%) dan 39 perempuan $(37,1 \%)$ yang bisa dilihat pada tabel 2. Hal ini sesuai dengan penelitian sebelumnya di Rumah Sakit Dr. Hasan Sadikin, Bandung dimana dari 62 anak yang memenuhi kriteria penelitian jenis kelamin lakilaki (56\%) lebih banyak dibandingkan dengan perempuan (44\%).Asfiksia neonatorum lebih banyak terjadi pada bayi laki-laki diduga terkait dengan perbedaan steroid gonad in utero sehingga kemampuan fetus laki-laki menghadapi stres lebih rendah. ${ }^{10,11}$

Penelitian ini didapatkan bahwa bayi baru lahir yang menderita asfiksia neonatorum dengan persalinan yang tertinggi yaitu dengan jenis persalinan seksio sesarea yakni 60 bayi $(57,1 \%)$ dari 105 bayi, sedangkan yang terendah menggunakan jenis persalinan ekstraksi forceps yakni 2 bayi $(1,9 \%)$ yang dapat dilihat pada tabel 3. Dari hasil uji chi-square didapatkan adanya hubungan bermakna dari hubungan jenis persalinan dengan asfiksia noenatorum $(\mathrm{P}=0,00)$.Hasil penelitian sebelumnya di RSUD Dr. Soetomo Surabaya pada periode Agustus-September 2009 juga meneliti hal yang sama dan menemukan bayi baru lahir dengan persalinan seksio sesarea yang mengalami asfiksia sebanyak $8,03 \%$ sedangkan bayi baru lahir dengan persalinan spontan yang mengalami asfiksia sebanyak $2,47 \%$. Penelitian lainnya juga dilakukan di Rumah Sakit Umum Haji Adam Malik, Medan dari tahun 2007 hingga 2010, berdasakan cara lahir, proposi terbesar adalah dengan seksio sesarea yaitu $53.7 \%$ dan yang paling sedikit ialah yang lahir secara normal yaitu $19.5 \%$ Hal ini disebabkan seksio sesarea yang diputuskan mendadak (CITO), tanpa perawatan pre-operatif yang memadai, dan tanpa direncanakan sebelumnya. Artinya seksio sesarea dilakukan apabila ibu maupun janin dalam keadaan darurat misalnya gawat janin, kelainan letak janin, eklamsia dan preeklamsia, partus lama, panggul sempit. ketuban pecah dini, oligohidramnion, makrosomia, dan cephalopelvic disproportion. Sedangkan ekstraksi forseps terendah di akibatkan jenis persalinan ini sangat berisiko terjadinya komplikasi seperti fraktur pada tulang kepala janin, luka pada kulit kepala janin, trauma jalan lahir, dan infeksi pasca persalinan sehingga sudah jarang digunakan. ${ }^{12-13}$

\section{Simpulan}

Dari penelitian ini disimpulkan bahwa :

1. Bayi yang menderita asfiksia neonatorum lebih banyak adalah laki-laki dibandingkan bayi perempuan..

2. Dari 105 bayi penderita asfiksia neonatorum didapatkan jenis persalinan tertinggi adalah seksio sesarea yakni 60 bayi $(57,1 \%)$.

3. Dari hasil dilakukan uji kemaknaan dengan chi-square maka didapatkan adanya hubungan bermakna antara jenis persalinan dengan asfiksia neonatorum $(\mathrm{P}=0,00)$ 


\section{Saran}

1. Perlu adanya sosialisasi kepada masyarakat terutama pada ibu hamil tentang asfiksia neonatorum agar dapat mencegah terjadinya asfiksia neonatorum.

2. Tersedianya sarana resusitasi dan peningkatan tenaga kesahatan yang terampil agar untuk meminimalkan mortalitas dan morbiditas.

\section{Ucapan Terima kasih}

Diberikan kepada dr. Audrey Wahani, SpA (K)dan dr. E. David Kaunang, $\operatorname{SpA}(\mathrm{K})$ dan kepada semua pihak baik secara langsung maupun tidak langsung telah menumbuhkan ide atau gagasan pada penulis sehingga penulis dapat menyelesaikan artikel ini.

\section{DAFTAR PUSTAKA}

1. Rusepno H, Husein A. Asfiksia neonatorum. Buku kuliah IKA 3.Bagian IKA FKUI 1985. h1072

2. Markum AH, Sofyan I, Husein A, Arwin A, Agus F, Sudigdo S. Asfiksia bayi baru lahir. Buku ajar IKA jilid 1.Bagian IKA FKUI Jakarta, 2002.h261-262.

3. Vera MM, Idham A. Gangguan fungsi multi organ pada bayi asfiksia berat. Sari Pediatri. 2003;5;(2):72-78.

4. Angka kejadian asfiksia neonatorum menurut WHO, diunduh di :

http://www.who.int/bulletin/vol umes/86/4/07-049924/en/

5. Lawn JE, Cousens S, Zupan J:

Lancet Neonatal Survival Steering Team. 4 million neonatal deaths: When? Where? Why? Lancet 2005; 365 (9462):891 -900.
6. London, Susan Mayor.

Communicable disease and neonatal problems are still major killers of children. BMJ 2005;330:748 (2 April), doi:10.1136/bmj.330.7494.748g.

7. Adhie NR, MS Kosim, Heru M. Asfiksia neonatorum sebagai faktor risiko gagal ginjal akut. Sari Pediatri. 2012;13(5):30510.

8. Badan Penelitian dan Pengembangan Departemen Kesehatan RI. Riset Kesehatan Dasar 2007. Jakarta: Departemen Kesehatan RI; 2008.h. 323

9. Neneng YBS. Hubungan jenis persalinan dengan kejadian asfiksia di RSUD dr.M Soewandhie Surabaya. Diunduh di

:http://alumni.unair.ac.id/kumpu lanfile/59123815491_abs.pdf

10. Indra JM, Dadang HS, Sjarif HE. Kesesuaian Skor New Ballard terhadap

Hari Pertama Haid Terakhir Ibu pada Bayi Cukup Bulan yang Lahir Asfiksia dan Tidak Asfiksia. J Indon Med Assoc, Volum: 61, Nomor: 10, Oktober 2011.

11. Hendrick B. Premature births decline in US [Internet] 2010 ; diunduh 3 Februari 2011. Diakses dari: http://www.medscape.com/view article/721675.

12. Dwi CF. Hubungan antara jenis persalinan seksio sesarea terhadap kejadian asfiksia pada bayi baru lahir. Diunduh di :http://alumni.unair.ac.id/kumpul anfile/44538815718 abs.pdf 
13. Maleeny P. Gambaran Asfiksia Neonatorum pada Bayi Baru Lahir di RSU Haji Adam Malik, Medan. Diunduh di http://repository.usu.ac.id/bitstre
am/123456789/31055/7/Cover.p

df 